\title{
Captures
}

Figures, théories et pratiques de l'imaginaire

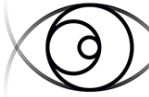

C A P T U R E S

\section{Volume 4 numéro 1}

\section{Vincent Lavoie}

Volume 4, Number 1, May 2019

Paroles diffamantes, images infamantes

URI: https://id.erudit.org/iderudit/1060151ar

DOI: https://doi.org/10.7202/1060151ar

See table of contents

Publisher(s)

Figura, Centre de recherche sur le texte et l'imaginaire

ISSN

2371-1930 (digital)

Explore this journal

Cite this document

Lavoie, V. (2019). Volume 4 numéro 1. Captures, 4(1).

https://doi.org/10.7202/1060151ar

\section{Article abstract}

À quelles conditions les œuvres littéraires et artistiques peuvent-elles porter atteinte à la réputation d'autrui? Poser la question comme l'y invite le présent dossier implique de rouvrir le débat philosophique sur la question des liens entre la littérature, l'art, la morale et la sphère juridique. Depuis les années 1990, ces interactions ont été largement discutées par les philosophes anglo-américains, dont les travaux ont été depuis lors traduits en français.
Tous droits réservés (C) Vincent Lavoie, 2019

\section{(c) (i) $\Theta$}

This document is protected by copyright law. Use of the services of Erudit (including reproduction) is subject to its terms and conditions, which can be viewed online.

https://apropos.erudit.org/en/users/policy-on-use/ 
Version enrichie de cet article : http://revuecaptures.org/node/3660

\section{Volume 4 numéro 1}

\section{Vincent Lavoie}

Résumé :

À quelles conditions les œuvres littéraires et artistiques peuvent-elles porter atteinte à la réputation d'autrui? Poser la question implique de rouvrir le débat philosophique sur la question des liens entre la littérature, l'art, la morale et la sphère juridique. Si la littérature française contemporaine fut à la source de plusieurs controverses, débats et procès situant l'acte d'écriture dans le champ des considérations morales, il en va de même de certaines œuvres artistiques qui dressent le portrait à charge des puissants de ce monde.

Under which conditions can literary works or art works bear offense upon a person's reputation? This issue's thematic dossier is a testament to the fact that asking such questions implies reopening the debate about the jurisdiction held by the Law on the field of art - literary or other. Indeed contemporary French literature has proven particularly apt at inducing controversies, debates, lawsuits and such, not unlike certain of the most notorious artistic works of the new century.

À quelles conditions les œuvres littéraires et artistiques peuvent-elles porter atteinte à la réputation d'autrui? Poser la question comme l'y invite le présent dossier dirigé par Ania Wroblewski implique de rouvrir le débat philosophique sur la question des liens entre la littérature, l'art, la morale et la sphère juridique. Depuis les années 90, ces interactions ont été largement discutées par les philosophes anglo-américains, dont les travaux ont été depuis lors traduits en français 1 . Voilà une heureuse initiative, car la littérature française contemporaine fut à la source de plusieurs controverses, débats et procès situant l'acte d'écriture dans le champ des considérations morales. De même de certaines œuvres artistiques qui, à la manière d'un Daumier au XIXe siècle, dressent le portrait à charge des puissants de ce monde. Le nu de Donald Trump réalisé en 2016 par Illma Gore s'impose immédiatement à l'esprit. On se souvient que l'artiste fut menacé de poursuite judiciaire pour avoir peint le milliardaire avec un micropénis. Cette peinture est injurieuse parce qu'elle laisse sous-entendre qu'il y a du vrai dans ce qu'elle montre.

L'infamie et la diffamation se nourrissent du réel. Qu'il s'agisse des « restes » de réalité dansLes Petits (2013) de Christine Angot, du fait divers (l'Affaire Grégory) qui inspira L'enfant d'octobre (2006) de Philippe Besson et "Sublime, forcément sublime Christine V. » (1985) de Marguerite Duras, de l'antisémitisme irriguant l'œuvre d'Edmond Picard (1836-1924), du récit d'expérience d'un deuil avec Le Bébé (2002) de Marie Darrieussecq ou de l'autobiographie compromettante de Min Kamp (2009) de Karl Ove Knausgård, l'outrage, s'il en est, a partie liée avec des réalités, des présomptions de vérité, des pseudo-vérités, des aveux et des secrets honteux. Retors, l'outrage se tapit dans l'écriture et se distille dans la lecture. L'injure est en revanche absolument 
frontale dans les œuvres d'Éric Pougeau, artiste visuel à l'honneur dans ce numéro, qui accueillent le lecteur avec des « fils de pute ", «putain d'ta race » et autres «salope ». Les mots sont crus, alors que les formes plastiques qui les portent sont celles de l'hommage et de la déférence. Alors prudence.

Ce numéro est le dernier placé sous la direction de l'actuelle équipe. Sébastien Roldan, secrétaire de rédaction et fidèle complice depuis les tout débuts de la revue, occupera sous peu des fonctions professorales à l'Université de Winnipeg. Celle-ci y gagnera un rédacteur chevronné et un brillant dix-neuviémiste. Je lui souhaite une riche et épanouissante carrière universitaire. Je m'en vais pour ma part veiller aux destinées du Centre de recherche sur le texte et l'imaginaire Figura, infrastructure abritant Captures depuis la fondation de cette dernière. Je quitte la revue heureux du travail accompli et très confiant pour son avenir. Le soutien qu'elle vient tout juste de recevoir de la part des grands organismes subventionnaires (FRQSC et CRSH) permet d'envisager celui-ci sous les meilleurs auspices. C'est Sylvain David, écrivain et professeur de littérature, membre du comité de rédaction de la revue depuis sa création, qui reprendra le flambeau de la direction. II sera épaulé par Fanny Bieth, chercheuse en histoire de l'art, qui agira à titre de secrétaire de rédaction. Sylvain et Fanny formeront une équipe de très grand talent. Je leur souhaite la plus cordiale des bienvenues.

Vincent Lavoie

Directeur

1. On doit ce travail à Carole Talon-Hugon (2011).

\section{Bibliographie}

TALon-Hugon, Carole. 2011. Éthique et esthétique. Perspectives anglo-saxonnes. Paris : Presses universitaires de France, $272 \mathrm{p}$. 